\title{
Current Status of Sexual Health and Rights Indicators in Iran: An Overview
}

\author{
Roksana Janghorban $^{1,2}$; Robab Latifnejad Roudsari ${ }^{3, *}$; Ali Taghipour ${ }^{4}$; Mahmoud Abbasi ${ }^{5}$ \\ ${ }_{1}^{1}$ Maternal-Fetal Medicine Research Centre, Department of Midwifery, School of Nursing and Midwifery, Shiraz University of Medical Sciences, Shiraz, IR Iran \\ ${ }_{2}^{2}$ Department of Midwifery, School of Nursing and Midwifery, Mashhad University of Medical Sciences, Mashhad, IR Iran \\ ${ }^{3}$ Research Center for Patient Safety, Department of Midwifery, School of Nursing and Midwifery, Mashhad University of Medical Sciences, Mashhad, IR Iran \\ ${ }_{5}^{4}$ Health Sciences Research Center, Department of Biostatistics and Epidemiology, School of Health, Mashhad University of Medical Sciences, Mashhad, IR Iran \\ 5 Medical Ethics and Law Research Center, Department of Medical Ethics, Shahid Beheshti University of Medical Sciences, Tehran, IR Iran \\ ${ }^{*}$ Corresponding Author: Robab Latifnejad Roudsari, Research Center for Patient Safety, Department of Midwifery, School of Nursing and Midwifery, Mashhad University of Medical \\ Sciences, Mashhad, IR Iran. Tel: +98-5138598016, Fax:+98-5138598016, E-mail: LatifnejadR@mums.ac.ir, rlatifnejad@yahoo.com
}

Received: October 4, 2014; Revised: December 21, 2014; Accepted: March 30, 2015

\begin{abstract}
Sexual health and rights indicators provide essential tools for monitoring the status of individuals' sexual health and its rights, in various countries. This paper discusses sexual health and rights indicators in Iran. The indicators under study are derived from similar indicators developed by Asian-Pacific Resource and Research Center for Women, for the 15th anniversary of the International Conference on Population and Development monitoring project. Four HIV-related and three other indicators, including legal age of marriage, median age of women at marriage, and status of violence against women (VAW) were examined in this study. Iran has made several achievements in combating HIV|AIDS, with the focus on injectable drug users, and has countered a series of challenges in the determination of VAW prevalence, the increase of high risk behavior in adolescents, and sexual education for this group. The most important message of this paper is that special attention to challenging issues in Iranian individuals' sexual health could promote their current status.
\end{abstract}

Keywords: Violence; Acquired Immunodeficiency Syndrome; Health Status Indicators

\section{Introduction}

Sexual health has been defined by the World Health Organization (WHO) as "a state of physical, mental, and social well-being, related to sexuality; it is not merely the absence of disease, dysfunction or infirmity". Sexual health is an important part of overall physical and mental wellbeing and has an impact on the quality of life for both men and women (1). Its importance is more pronounced in Iran because the unspoken climate around sexual issues, which originates from the sociocultural status of the country, leads to embarrassment and discomfort in discussing sexual health (2).

To achieve and sustain sexual health, the sexual rights of all persons must be respected, protected, and fulfilled. The WHO has defined sexual rights as the right of all persons to access the highest possible standard of sexual and reproductive health care services and information; to respect bodily integrity; to choose a partner; to engage in sexual relations by mutual consent; to decide whether or not to have children; and to engage in a satisfying, secure, and gratifying sexual life (1).

Indicators are ways to measure the performance of a system (3). It seems that sexual health and rights indicators could generally express an overall viewpoint of the government commitments towards improving its individuals' sexual health.

In this article, authors examined seven sexual health and rights indicators, which were introduced by AsianPacific Resource and Research Center for Women (ARROW), a regional non-profit women's non-governmental organization (NGO) for the 15th anniversary of the International Conference on Population and Development $($ ICPD + 15) monitoring project in the Asian-Pacific region. These indicators consist of 1) status of violence against women (VAW), 2) legal women/men's age of marriage, 3) median age at marriage for women (age group 25 - 49), 4) estimated number of adults and children living with HIV, 5 ) estimation of HIV prevalence in adults (age group 15 $49), 6$ ) percentage of adults and children with advanced HIV infection receiving antiretroviral therapy (ART), and 7) estimated number of women aged $\geq 15$ living with HIV (4). Although these indicators have no universal validity for all world regions, they provide an accessible tool for evaluating sexual health and rights in different countries. Therefore, this study was conducted to examine current status of sexual health and rights in Iran, using the aforementioned indicators.

In several local studies, the prevalence of domestic violence has been reported to $15-43.7 \%$ for physical, 30.9 $42.4 \%$ for sexual, and 81.5 - $82.6 \%$ for psychological abuse, in various regions of Iran (5-7).

In the latest amendment of article 1041, legal age of marriage for women and men was determined at 13 and 15

Copyright ( 2 2015, Iranian Red Crescent Medical Journal. This is an open-access article distributed under the terms of the Creative Commons Attribution-NonCommercial 4.0 International License (http://creativecommons.org/licenses/by-nc/4.0/) which permits copy and redistribute the material just in noncommercial usages, provided the original work is properly cited. 
years, respectively (8). In 2012, the mean age at marriage for women was reported 24 years, in Iran (9). According to the data of the 2011 National Population and Housing Census of Iran, 1.74 and 0.48 percent of women and men, aged less than 15 years old, have been married at least once (10). According to the United Nations Program on HIV and AIDS (UNAIDS) report in 2013, the estimated number of people living with HIV in Iran was 70000 (47000 $110000)$, although, based on the data of case registry system, 23497 people were infected with HIV until September 21st, 2011 (11, 12). The latest estimate showed that HIV prevalence rate in adults aged 15 - 49 years was $0.1-0.2 \%$, and it remained constant from 2011 to 2013. The estimated number of women aged $\geq 15$, living with HIV, in Iran, was 19000 in 2013 (11-13). The United Nations General Assembly Special Session (UNGASS) country progress report, in 2012, showed that $7.8 \%$ of the total people who needed ART, in Iran, received it. The people were comprised of 684 females and 2068 males (13).

\section{Arguments}

Despite special attention of the Islamic Republic of Iran to fulfill sexual health and rights, several problems impede their achievement. For instance, domestic violence prevalence cannot accurately be determined because of underreporting, sampling selection bias, and different data collecting tools. According to a qualitative research, experts believe that the existing laws of the country introduce an unclear definition of domestic violence against women. The ambiguous rules with weak law enforcement are the main legal obstacles to prevent and deal with the violence (14).

Although Iranian laws have determined an age limit for marriage and the mean age at marriage for Iranian women was constant from 2010 to 2012 (9), the possibility of early marriage and its adverse impacts have remained a challengeable issue. Information from the Center of Disease Control of the Ministry of Health and Medical Education of Iran indicated that the rates of high risk behaviors, which could lead to HIV/AIDS, are increasing quickly (15). Additionally, access to various communication technologies has changed social traditions about prohibition of pre-marital sex in young people $(16,17)$. Sexual relationships could increase the likelihood of HIV infection, maternal mortality, and domestic violence, in the age group (18). According to the World Bank report, in 2012, adolescence fertility rate was 31 births per 1000 married and single women aged 15 - 19 years, in Iran. Despite a constant rate from 2010 to 2012 (19), the situation confirms the necessity of sexual health education and provision of sexual and reproductive health services, for adolescents (20). Several studies showed that cultural taboos surrounding sexuality are major obstacles to sexual health education and services for the group $(20,21)$. Although education in schools can provide an opportunity to transfer correct information about sexual and repro- ductive health and rights, fears of parents' objection and lack of legal support lead to banning or restricting the education (21).

Iran has provided an effective model entitled "Triangular Clinics" for HIV prevention, care, and support in injectable drug users, the most important group influencing the prevalence of HIV in the country. The clinics provide harm reduction interventions (needle syringe programs and methadone maintenance treatment), sexually transmitted infection services, and care/support for people living with HIV/AIDS (22). Consequently, 91.72\% of all people who injected drugs used a sterile needle on their last injection. The progress was very significant in comparison with the previous report, in 2010, which was 74.5\% (8).

Despite the implementation of the National Harm Reduction program, sexual transmission of HIV has become another top concern in the prevention program. Although the use of condom in sexual relationships represents one of the preventive strategies in the transmission of HIV, studies have shown that nearly $50 \%$ of women and men aged 15 - 49 years with multiple sexual partners did not use condoms during their last sexual intercourse. The indicator was reported $15 \%$ and $57 \%$ in injectable drug users and female sex workers, respectively. It should be noted that most of the study population in the sex worker group was composed of women integrated in specific Drop in Centers, who have received a certain amount of information. Therefore, generalizing the findings to all female sex workers should be treated with caution $(11,12)$. Furthermore, the accessible evidence indicates protective behaviors based on condom use were low among at risk populations $(23,24)$. Additionally, "Lack of perceived threat, absence of protective motivation, inadequate knowledge, perceived lack of control, negative attitudes towards condom, misperception, unsupportive environments, and cultural norms" have been identified as barriers to condom use among at risk women (25). The situation could be a trigger for planning a better targeted education of high-risk groups.

Other best practices for combating HIV/AIDS in Iran consist of counseling hotlines for individuals, positive clubs for people living with, and affected by HIV, counseling centers for vulnerable women, educational programs for inmates, and protection of anti-discrimination laws for people living with HIV $(12,13)$. In terms of HIV treatment, despite the increased number of individuals who receive ART, there is a discordance between the growth coverage of treatment and need for ART. Several experts believe that this problem has occurred due to software overestimation in need of ART (12). This is because the AIDSrelated mortality patterns from 2005 to 2011 showed no change or decrease of less than $25 \%$, in the country (13).

\section{Conclusions}

In conclusion, Iran has successfully made certain achievements in sexual health and rights, whereas in the 
future steps, focusing on critical challenges could fulfill Iranian individuals' sexual health. Some of these include: delivering HIV preventive services to the "hidden" population of injectable drug users and sex workers, investments in HIV treatment with pace of increasing demand, engaging men and youth in national AIDS programs and anti-VAW plans in format of youth-friendly and malefriendly services, monitoring the implementation of sexual health education for adolescents with parental supervision in schools, integrating anti-VAW programs in public health systems, supporting NGOs with culturally sensitive activities in VAW-related matters for the target group of men, and providing evidence and populationbased data in relation to VAW.

\section{Acknowledgements}

This article is part of a PhD thesis in Reproductive Health focused on Iranian women's sexual and reproductive health rights. Authors acknowledge Mashhad University of Medical Sciences, Mashhad, Iran, for financial support.

\section{Authors' Contributions}

Study concept, search of documents, drafting of the manuscript, and critical revision of the manuscript for important intellectual content: Roksana Janghorban and Robab Latifnejad Roudsari. Study concept, drafting of the manuscript, and critical revision of the manuscript for important intellectual content: Ali Taghipour, Mahmoud Abbasi.

\section{Funding/Support}

This article was funded by Vice Chancellor for Research, Mashhad University of Medical Sciences, Mashhad, Iran (grant number: 910141).

\section{References}

1. Lottes IL. Sexual rights: meanings, controversies, and sexual health promotion.J Sex Res. 2013;50(3-4):367-91.

2. Merghati Khoei E, Whelan A, Cohen J. Sharing beliefs: what sexuality means to Muslim Iranian women living in Australia. Cult Health Sex. 2008;10(3):237-48.

3. Flowers J, Hall P, Pencheon D. Public health indicators. Public Health. 2005;119(4):239-45.

4. Asian-Pacific Resource and Research Center for Women . ARROW publishes a guide on strategic SRHR indicators for advocates.. Available from: http://www.arrow.org.my/newsletter/2013/dec/edm1.htm/.

5. Ghazizadeh A. Domestic violence: a cross-sectional study in an Iranian city. East Mediterr Health J. 2005;11(5-6):880-7.

6. Faramarzi M, Esmailzadeh S, Mosavi S. Prevalence and determi- nants of intimate partner violence in Babol City, Islamic Republic of Iran. East Mediterr Health J. 2005;11(5-6):870-9.

7. Vakili M, Nadrian H, Fathipoor M, Boniadi F, Morowatisharifabad MA. Prevalence and determinants of intimate partner violence against women in Kazeroon, Islamic Republic of Iran. Violence Vict. 2010;25(1):116-27.

8. Physical Capacity for Marriage, Points from Civil Law and Related Regulations, The Amendment of Article No.1041. 2002.

9. World Economic Forum . The global gendergap report.. Available from: http://www3.weforum.org/docs/WEF_GenderGap_Report_2012.pdf.

10. Statistical Centre of Iran.. Iranian Population and Housing Census. Iran: Statistical Centre of Iran; 2013.

11. The Joint United Nations Programme on HIV and AIDS . HIV and AIDS estimates. 2013. Available from: http://www.unaids.org/en/ regionscountries/countries/islamicrepublicofiran.

12. The Joint United Nations Programme on HIV and AIDS . Islamic Republic of Iran AIDS Progress Report, On Monitoring of the United Nations General Assembly Special Session on HIV and AIDS. Iran: The Joint United Nations Programme on HIV and AIDS; 2013.

13. The Joint United Nations Programme on HIV and AIDS . Global report, UNAIDS report on the global AIDS epidemic.; 2013.

14. Ahmadi B, Nasseri S, Alimohamadian M, Shams M, Ranjbar Z, Shariat M, et al. Views of Tehrani couples and experts on domestic violence against women in Iran: A qualitative research. Journal of School of Public Health and Institute of Public Health Research. 2008;6(2):67-81.

15. Najarkolaei FR, Niknami S, Aminshokravi F, Tavafian SS, Joneidi Jafari NA, Golabchi A. Promoting sexual abstinence intention among female university students: A quasi-experimental study. J Res Med Sci. 2013;18(1):37-43.

16. Farahani FK, Cleland J, Mehryar AH. Associations between family factors and premarital heterosexual relationships among female college students in Tehran. Int Perspect Sex Reprod Health. 2011;37(1):30-9.

17. Mohammadi MR, Mohammad K, Farahani FK, Alikhani S, Zare M, Tehrani FR, et al. Reproductive knowledge, attitudes and behavior among adolescent males in Tehran, Iran. Int Fam Plan Perspect. 2006;32(1):35-44.

18. Svanemyr J, Chandra-Mouli V, Christiansen CS, Mbizvo M. Preventing child marriages: first international day of the girl child "my life, my right, end child marriage". Reprod Health. 2012;9:31.

19. Janghorban R, Taghipour A, Latifnejad Roudsari R, Abbasi M. Women's empowerment in Iran: a review based on the related legislations. Glob J Health Sci. 2014;6(4):226-35.

20. Mosavi SA, Babazadeh R, Najmabadi KM, Shariati M. Assessing Iranian adolescent girls' needs for sexual and reproductive health information. JAdolesc Health. 2014;55(1):107-13.

21. Latifnejad Roudsari R, Javadnoori M, Hasanpour M, Hazavehei SM, Taghipour A. Socio-cultural challenges to sexual health education for female adolescents in Iran. Iran J Reprod Med. 2013;11(2):101-10.

22. Razzaghi E, Nassirimanesh B, Afshar P, Ohiri K, Claeson M, Power R. HIV/AIDS harm reduction in Iran. Lancet. 2006;368(9534):434-5.

23. Hajiabdolbaghi M, Razani N, Karami N, Kheirandish P, Mohraz M, Rasoolinejad M, et al. Insights from a survey of sexual behavior among a group of at-risk women in Tehran, Iran, 2006. AIDS Educ Prev. 2007;19(6):519-30.

24. Ramezani Tehrani F, Malek-Afzali H. Knowledge, attitudes and practices concerning HIV/AIDS among Iranian at-risk sub-populations. East Mediterr Health J. 2008;14(1):142-56.

25. Lotfi R, Ramezani Tehrani F, Yaghmaei F, Hajizadeh E. Barriers to condom use among women at risk of HIV/AIDS: a qualitative study from Iran. BMC Womens Health. 2012;12:13. 